\title{
Social Anxiety and Positive Emotions: A Prospective Examination of a Self-Regulatory Model With Tendencies to Suppress or Express Emotions as a Moderating Variable
}

\author{
Todd B. Kashdan, William E. Breen \\ George Mason University
}

\begin{abstract}
The purpose of the present study was to examine social anxiety as a predictor of positive emotions using a short-term prospective design. We examined whether the effects of social anxiety on positive emotions are moderated by tendencies to openly express or supress emotions. Over the course of a 3month interval, people with excessive social anxiety endorsed stable, low levels of positive emotions. In addition, people with low social anxiety who frequently display their emotions openly, whether negative or positive, reported the greatest increases in positive emotions. Similar results were found when using a measure of emotion suppression (low social anxiety and less tendency to rely on these types of regulatory acts led to the greatest positive emotions). These social anxiety main and interactive effects could not be attributed to depressive symptoms. Our findings suggest that relations between social anxiety and positive emotional experiences over time are best understood in the context of meaningful individual differences such as affect regulatory strategies.
\end{abstract}

ENGAGING IN VARIOUS TYPES of social activities and feeling a sense of connectedness with others is one of the most important mechanisms in the

This research was supported by National Institute of Mental Health grant MH-73937 to Todd B. Kashdan. Portions of this article were presented at the 2005 Annual Convention of the Association for Behavioral and Cognitive Therapies. We express our gratitude to Jeffrey Volkmann and other members of our research laboratory in the data collection stage.

Address correspondence to Todd B. Kashdan, Department of Psychology, MS 3F5, George Mason University, Fairfax, VA 22030, USA; e-mail: tkashan@gmu.ed, Web site: http://mason.gmu/ tkashdan.

0005-7894/07/0001-0012\$1.00/0

(C) 2007 Association for Behavioral and Cognitive Therapies. Published by Elsevier Ltd. All rights reserved. promotion of psychological, social, and physical well-being (Baumeister \& Leary, 1995; House, Landis, \& Umberson, 1988). Excessive fear and avoidance of interacting with other people because of concerns about being evaluated leads to less social activity and connectedness than desired (Baumeister \& Tice, 1990). People with excessive social anxiety have been shown to have poor relationships or a relative absence of social connections (Alden \& Taylor, 2004; Wittchen \& Beloch, 1996). The conflict (whether real or imagined) between wanting to connect with others and form satisfying relationships but being unable to do so might erode opportunities for positive experiences. In addition, devoting extensive time and effort to avoidance behaviors and attempts to regulate or conceal anxious feelings may reduce a person's life space and the ability to be fully present during potentially enjoyable activities (e.g., Clark \& Wells, 1995; Leary \& Kowalski, 1995).

For over a decade, theory and data have suggested that elevated negative affect is a common characteristic of anxiety and depression, whereas diminished positive affect is specific to depression (and not a feature of anxiety; Burns \& Eidelson, 1998; Clark, Steer, \& Beck, 1994; Clark \& Watson, 1991; Davidson, 1994; Watson et al., 1995). However, more recent work challenges the specificity of diminished positive experiences to depression and suggests that this same affective profile is consistent with social anxiety (T. Brown, Chorpita, \& Barlow, 1998; Kashdan, 2007; Kashdan \& Steger, 2006; Watson, Clark, \& Carey, 1988). Based on 17 studies, a recent meta-analysis (Kashdan, 2007) revealed that excessive social anxiety has a reliable, moderate inverse relation with positive emotions and curiosity even after statistically controlling for variance attributable to 
depressive symptoms and disorders. This is a useful starting point; however, there is reason to believe that dispositional social anxiety may operate synergistically with ways in which people attend to, regulate, express, and accept emotional experiences (Eifert \& Forsyth, 2005; Hayes, Luoma, Bond, Masuda, \& Lillis, 2006). Specifically, excessive social anxiety may become particularly problematic in the presence of chronic, rigid tendencies to manage and conceal emotional experiences and the situations that elicit them. Socially anxious people are confronted with approach-avoidance conflicts between the desire to make a good impression and be accepted by others and beliefs that (a) rejection is highly probable and costly, (b) socializing will cause unwanted, negatively evaluated, thoughts, feelings, and sensations, and (c) concealing emotional experiences and inhibiting emotional expressions will render them more socially attractive (e.g., less vulnerable) and minimize negative social outcomes such as rejection. For these individuals, limited self-regulatory resources (e.g., physical stamina, cognitive processing capacity) may be overexerted and depleted by chronic attempts to avoid anxious feelings and conceal their expression (Muraven \& Baumeister, 2000; Vohs, Baumeister, \& Ciarocco, 2005).

We consider this a "joint vulnerability" model such that excessive social anxiety and habitual attempts to suppress emotional experiences are proposed to be a "toxic" combination. When people purposely try to inhibit ongoing anxious responses (e.g., negatively evaluated thoughts), they tend to experience a rebound effect or increase in the exact responses that are trying to be avoided (e.g., Behar, Vescio, \& Borkovec, 2005; Harris, 2001; Wegner, Schneider, Carter, \& White, 1987). Although the strategic suppression of emotional experiences does not appear to reduce negative emotions, there is evidence that this process dampens or diminishes positive emotions (Gross \& Levenson, 1997; Strack, Martin, \& Stepper, 1988). The deleterious consequences of suppressing emotional experience and expression are expected to be amplified for people experiencing intense and frequent social anxiety.

Consider the romantically single, socially anxious adult who is conflicted about attending a party. Although the person may be excited and curious about the possibility of sharing experiences, laughing, flirting, and maybe even finding a romantic partner, he or she may also be burdened with unwanted anxious thoughts, feelings, and bodily sensations stemming from the anticipated threat of being ignored or rejected by others. If he or she avoids the party (or attends but withdraws into a corner, etc.), then he or she not only reinforces effortful avoidance as a strategy to limit contact with anxious thoughts, feelings, and sensations, but also drifts further away from the possibility of social connectedness. Being in a prevention mode such that one avoids social interactions, acts innocuously, or tries to suppress thoughts, words, or behavioral intentions serves the purpose of preventing imminent rejection (e.g., Arkin, 1981; Clark \& Wells, 1995). However, there are several response costs related to effortful attempts to control social anxiety and engaging in safety behaviors that include being inordinately self-focused and inauthentic, feeling regret and pain associated with unsatisfied social curiosity, and minimizing the possibility of feeling a sense of social belonging or generating intimacy Additionally, an extreme focus on controlling and concealing frequent and intense feelings of anxiety would drain and deplete emotional and physical resources, leaving limited resources available for completing the task at hand (e.g., maintaining a conversation).

Data suggest that people with excessive social anxiety are more likely to control and suppress their thoughts and inhibit the expression of positive and negative emotions than their less anxious peers (e.g., Fehm \& Margraf, 2002; Kashdan \& Steger, 2006; Turk, Heimberg, Luterek, Mennin, \& Fresco, 2005). Yet, people with excessive social anxiety vary in their tolerance of distress and situations that might elicit strong emotional reactions (e.g., Nezlek \& Leary, 2002). It is hypothesized that people who make life choices with the function of avoiding and concealing anxiety establish a behavioral pattern that interferes with progress toward other valued life goals (e.g., feeling close and connected to others and sharing in positive events) and that leads to a more insulated and depleted existence (i.e., life in a social cocoon).

Though there are few empirical tests of this joint vulnerability model, the initial evidence is supportive (Feldner, Zvolensky, Stickle, Bonn-Miller, \& Leen-Feldner, 2006; Vujanovic, Zvolensky, Bernstein, Feldner, \& McLeish, 2007). However, only one study has focused on the interactive effect of social anxiety and tendencies to conceal emotions on positive emotions and events (Kashdan \& Steger, 2006). Social anxiety was measured on the dispositional and daily level, a measure of emotion suppression was used to assess the unwillingness to express emotions freely, and positive experiences and events were measured on a daily basis for 3 weeks. Social anxiety was associated with less daily positive emotions and curiosity and fewer everyday positive events. These findings remained significant even after controlling for global negative affect and depressive symptoms (with the exception of positive 
events). ${ }^{1}$ Supporting our conceptual framework on the cost of being unwilling to experience and express emotions freely, emotion suppression moderated relations between social anxiety and positive experiences and events. Among people defined as socially anxious, the least number of positive events was reported on days when they felt particularly socially anxious and tended to inflexibly suppress emotions. Thus, the pernicious impact of social anxiety on positive experiences and events appears to be exacerbated by chronic and inflexible attempts to suppress emotional experiences, supporting a joint vulnerability model of psychopathology.

As a complement to the joint vulnerability model, it appears that the relative absence of social anxiety may not be sufficient for a high frequency of enjoyable or meaningful experiences. As such, greater tendencies to accept and openly express emotions are proposed to be the critical element leading less socially anxious individuals to increased positive psychological functioning (Hayes, Wilson, Gifford, Follette, \& Strosahl, 1996; Hayes et al., 2006). In the study by Kashdan and Steger (2006), people reported the greatest number of positive events on days when they felt less socially anxious and did not attempt to hide or suppress their emotions. That is, experiencing the greatest frequency of positive events in everyday life was a function of low social anxiety and a greater willingness to accept, tolerate, and express emotions as they naturally arise. These data provide preliminary evidence for an interactive model of thriving within the context of social anxiety and emotion regulation.

Less socially anxious individuals are expected to report more frequent and intense positive emotions than their more anxious peers. Theoretically, greater tendencies to express and outwardly display emotions should enhance the sensitivity to and savoring of positive life events. By openly expressing and sharing positive feelings with others, positive events and their mood-boosting effects can be prolonged. Accepting and openly expressing positive emotions serves the function of clearly delineating pleasurable and meaningful events (Langston, 1994). In turn, this process leads to more organized positive memories that can be more easily retrieved, savored, and

\footnotetext{
${ }^{1}$ Relations between social anxiety and daily curiosity were not reported in the article (Kashdan \& Steger, 2006). Thus, to be specific, after grand centering predictors, trait social anxiety was negatively related to daily curiosity and exploratory behavior, $b=-.11, t(95)=$ $-3.21, p<.005$, even after controlling for global negative affect, $b=$ $-.10, t(94)=-2.48, p<.05$, and depressive symptoms, $b=-.08$, $t(94)=-2.15, p<.05$. In contrast, after controlling for trait social anxiety, global negative affect and depressive symptoms failed to significantly predict daily curiosity.
}

strategically used to sustain or enhance positive emotions. There are also social benefits of sharing positive events with others. Shared positive events can be attributed to the relationship itself and thereby strengthen social bonds (Aron, Norman, Aron, McKenna, \& Heyman, 2000). Also, sharing information about positive personal events can enhance meaningful connections with others (e.g., discovering commonalities) and increase intimacy. People with less social anxiety who express their emotions openly activate these positive psychological processes (e.g., savoring, capitalization) with the likely consequence of having more frequent and intense positive emotions over time. Inhibiting the expression of emotions disrupts these processes and may result in a plateau or erosion of positive emotions over time.

\section{The Current Study}

This was the first study to use a short-term prospective design to examine the effects of social anxiety and emotion regulation variables on positive emotions. We hypothesized that tendencies to suppress emotions would moderate any prospective relations between social anxiety and positive emotions. People with excessive social anxiety who suppress or hide their emotions were expected to experience the greatest erosion in positive emotional experiences over time. Alternatively, social anxiety might have a stable, inverse relation with positive emotions. Impairment may be a function of adopting an avoidance-based lifestyle that reduces opportunities for positive experiences and social connectedness. This avoidance-based lifestyle may be adopted early in life and thereby lead to stable, low levels of pleasure, engagement, and meaning in life (without continual erosion). As a complementary interactive model, we hypothesized that less socially anxious people who tolerate and express their emotions openly would show the greatest increases in positive emotions over time.

We also examined whether emotion suppression and expression are distinct or best understood as endpoints on a single continuum. Expressive suppression has been defined as strategic attempts to intentionally disrupt or minimize emotional experience and expression (Gross, 1998; Gross \& John, 2003). This is considered a response-focused strategy because it is employed when emotions are active to modulate subjective, behavioral, and physiological responses. Whether intentionally used or activated automatically, people who are less emotionally expressive appear to conceal or hide ongoing emotional experiences. Experimental and correlational studies support the convergence of these constructs (see Gross \& John, 2003, and John \& Gross, 2004, for reviews). However, people who are less apt to suppress emotions are not inherently more 
willing to express and outwardly display their emotions in different situations. In response to this theorizing, we empirically evaluated the independence of emotion suppression and expression as a precursor to testing moderation hypotheses.

Few studies exist on the differential effects of regulating negative compared to positive emotions. Whereas strategic attempts to suppress negative emotions has been shown to amplify negative emotions (e.g., Behar et al., 2005; Feldner, Zvolensky, Eifert, \& Spira, 2003), suppressing positive emotions has been shown to dampen positive emotions (Gross \& John, 2003; Gross \& Levenson, 1993, 1997). Other work suggests that people who are more outwardly expressive of both positive and negative emotions derive more interpersonal benefits than less expressive peers. Both positive and negative emotions serve as ways to signal and respond to other people (Frijda, 1986). Problems are not due merely to levels of emotional expression but may arise from extreme ratios of negative to positive emotion expression, nonresponsiveness to distress communicated by partners, and negative emotional reactions to partners' negative affect (e.g., Cartensen, Gottman, \& Levenson, 1995; Levenson \& Gottman, 1985). Although being more expressive appears to be beneficial in some contexts, the effects of emotional expression may be compromised for people with excessive social anxiety burdened by frequent and intense negative emotions and thoughts (e.g., ruminating about social events and anticipatory anxiety). There is preliminary support for this interactive effect on relationship outcomes (e.g., Kashdan, Volkmann, Breen, \& Han, 2007).

In sum, the current study examined temporal relations between social anxiety and positive emotions and the possible moderating influences of emotion suppression and expression.

\section{Method}

\section{PARTICIPANTS}

Participants were undergraduate students enrolled in psychology courses at a large, public, Mid-Atlantic university. Students received research credit for their participation and were required to complete an initial survey and 3-month follow-up survey to receive full course credit.

Participants in the current examination were individuals who completed both waves of data (initial survey and 3-month follow-up). At Time 1 (T1), a total of 148 individuals participated. At Time 2 (T2), 145 of the individuals from T1 completed the 3 -month follow-up survey (98\% retention rate). The T2 sample was comprised of 109 women $(75.2 \%)$ and 36 men $(24.8 \%)$. The majority were Caucasian
$(69 \%)$, with the remaining participants defining themselves as Hispanic/Hispanic-American (6.3\%), Asian/Asian-American (5.6\%), Middle-Eastern $(5.6 \%)$, African-American (3.5\%), Mixed or Other $(7.7 \%)$, and $2.1 \%$ providing no response. Participants' ages ranged from 18 to 46 years, with a mean of $23.18(S D=6.08)$. Participants in the current study constitute a subsample of a larger research project.

\section{PROCEDURE}

Participants completed a confidential Internet-based survey and were not asked to provide information that could identify them (i.e., names, birthdates). At T1, all participants completed several different predictor and outcome questionnaires (see Measures) and gave consent to be contacted for future studies. Three months later, at T2, participants were contacted via email and provided with a Web link to access the follow-up survey. The T2 survey was comprised of the same predictor and outcome questionnaires found in the T1 survey.

The Internet survey company (PsychData) used for data collection maintains the highest security standards, including encrypted data transfer, password-required access to data, and a secure survey environment (answers are written on a secure server with no traces on individual computers and individual IP addresses were not collected).

\section{Measures}

\section{PREDICTOR QUESTIONNAIRES}

Trait social anxiety. The 19-item Social Interaction Anxiety Scale (SIAS; Mattick \& Clarke, 1998) assesses tendencies to be fearful and avoidant of social situations based on concerns related to possible negative evaluation and rejection. Responses are provided using a 5-point Likert scale, rated from 0 (not at all) to 4 (extremely). The SIAS demonstrates internal consistency $(\alpha=.88-.94)$ and stability across a 4-week period of time $(r=.92$; Mattick \& Clarke, 1998) and reliably differentiates between individuals diagnosed with social anxiety disorder and other anxiety disorders (E. Brown et al., 1997) as well as nonclinical controls (Heimberg, Mueller, Holt, Hope, \& Liebowitz, 1992). The SIAS has also demonstrated adequate sensitivity (.93) and specificity (.60) in previous research (Peters, 2000).

Depressive symptoms. The 21-item Beck Depression Inventory-II (BDI-II; Beck, Steer, \& Brown, 1996) assesses the severity of depressive symptoms. Responses are provided using a 4-point Likert scale, with higher scores representing more severe depressive symptoms. In previous research, the BDI-II demonstrated excellent internal validity $(\alpha=.93$ for university sample) and 1-week test-retest reliability 
$(r=.93$; Beck et al., 1996) and reliably distinguished between clinical and nonclinical samples (Sprinkle et al., 2002).

Trait emotion suppression. The 10-item Emotion Regulation Questionnaire (ERQ; Gross \& John, 2003) measures different ways that individuals tend to manage their emotions. In the current study, only the 4-item Emotion Suppression Subscale of the ERQ was used. The Suppression Subscale assesses tendencies to inhibit or conceal the expression of emotions being experienced (items included: "When I am feeling positive emotions, I am careful not to express them"; "I control my emotions by not expressing them"; "When I am feeling negative emotions, I make sure not to express them"; and "I keep my emotions to myself"). Responses are provided using a 7-point Likert scale; rated from 1 (strongly disagree) to 7 (strongly agree). The ERQ Suppression Subscale has demonstrated acceptable internal reliability $(\alpha=.73)$ and 3-month test-retest reliability $(\mathrm{r}=.69)$ in five previous studies using college samples (Gross \& John, 2003).

Trait emotion expressiveness. The 16-item Berkeley Expressivity Questionnaire (BEQ; Gross \& John, 1995) assesses individual differences in the willingness to accept and openly express emotion experiences. The BEQ consists of three subscales that measure the tendency to express positive emotions, the tendency to express negative emotions, and the intensity of impulses to express emotions. Responses are provided using a 7-point Likert scale, rated from 1 (strongly agree) to 7 (strongly disagree). In this study, we used the positive and negative expressivity subscales. Sample items from the Positive Expressivity Subscale include, "Whenever I feel positive emotions, people can easily see exactly what I am feeling" and "I laugh out loud when someone tells me a joke that I think is funny." Sample items from the Negative Expressivity
Subscale include, "It is difficult for me to hide my fear" and "No matter how nervous or upset I am, I tend to keep a calm exterior." The BEQ Positive and Negative Expressivity subscales have been used in several previous studies with college-aged samples and demonstrate adequate internal consistency $(\alpha=.71$ and .72, respectively) and 2-month test-retest reliability $(r=.78$ and .71 , respectively; Gross \& John, 1995, 1997).

Positive emotions. The 20 -item trait version of the Positive and Negative Affect Schedule (PANAS; Watson, Clark, \& Tellegen, 1988) assesses two distinct dimensions of general emotions. The 10item Positive Affect Subscale assesses activated positive emotions (e.g., excited, joy) and the 10item Negative Affect Subscale assesses activated negative emotions (e.g., anxious, jittery). Responses are provided using a 5-point Likert scale and participants are asked how they generally feel, rated from 1 (very slightly) to 5 (extremely). The PANAS is one of the most widely used measures of positive and negative emotions. The PANAS has demonstrated consistent independence between the two affect subscales as well as excellent psychometric properties (Watson, 2000).

\section{Results}

\section{PRELIMINARY ANALYSES}

Means, standard deviations, and alpha coefficients for all scales at T1 and T2 are reported in Table 1. All scales had acceptable internal consistency. Participants' average social anxiety scores at T1 $(M=23.31 ; S D=13.83)$ were similar to other large nonclinical samples (Heimberg et al., 1992; Mattick \& Clarke, 1998) and scores at least one standard deviation above the mean were similar to clinical samples (E. Brown et al., 1997).

Table 1

Means, Standard Deviations, Internal Consistency Coefficients for, and Zero-Order Relations Between All Variables

\begin{tabular}{|c|c|c|c|c|c|c|c|c|}
\hline & 1 & 2 & 3 & 4 & 5 & 6 & 7 & 8 \\
\hline 1. T1 SIAS & - & $.85^{\star \star \star}$ & $-.41^{\star \star \star}$ & $-.30^{\star \star \star}$ & $.30^{\star \star \star}$ & -.11 & -.13 & $.49^{\star \star *}$ \\
\hline 2. T2 SIAS & - & - & $-.35^{\star \star \star}$ & $-.38^{\star \star \star}$ & $.27^{\star \star}$ & -.15 & -.11 & $.44^{\star \star *}$ \\
\hline 3. T1 PA & - & - & - & $.61^{\star \star \star}$ & $-.18^{*}$ & $-.25^{\star \star}$ & -.03 & $-.60^{\star \star \star}$ \\
\hline 4. T2 PA & - & - & - & - & $-.18^{*}$ & $-.21^{\star}$ & .08 & $-.43^{\star \star \star}$ \\
\hline 5. T1 Suppression & - & - & - & - & - & $-.53^{* * *}$ & $-.60^{\star * *}$ & $.24^{\star \star}$ \\
\hline 6. T1 BEQ-positive & - & - & - & - & - & - & $.52^{\star \star *}$ & -.12 \\
\hline 7. T1 BEQ-negative & - & - & - & - & - & - & .03 & - \\
\hline 8. T1 BDI-II & - & - & - & - & - & - & - & - \\
\hline$M$ & 23.31 & 21.49 & 33.68 & 34.23 & 12.74 & 21.95 & 23.58 & 11.96 \\
\hline$S D$ & 13.83 & 12.47 & 6.37 & 6.89 & 4.89 & 4.14 & 6.85 & 9.46 \\
\hline$\alpha$ & .86 & .86 & .85 & .87 & .74 & .74 & .76 & .90 \\
\hline
\end{tabular}

Note. ${ }^{*} p<.05 .{ }^{* *} p<.01$. ${ }^{* * *} p<.001$. All $p$-values were two-tailed. T1=Time 1; T2=Time 2; SIAS=Social Interaction Anxiety Scale; $\mathrm{PA}=$ Positive and Negative Affect Schedule, Positive Affect subscale; BEQ-positive=Berkeley Expressivity Questionnaire-Positive Expression Subscale; BEQ-negative=Berkeley Expressivity Questionnaire-Negative Expression Subscale; BDI-II=Beck Depression Inventory-II. 
Table 2

Hierarchical Regression Models of Social Anxiety Predicting Changes in Positive Emotions With Emotion Suppression and Expression as Moderators

\begin{tabular}{|c|c|c|c|c|c|c|c|}
\hline \multicolumn{8}{|c|}{ Moderator: Emotion Suppression } \\
\hline Step & & $\mathrm{b}$ & $\mathrm{SE}_{\mathrm{b}}$ & $\mathrm{pr}$ & $\mathrm{t}$ & $\Delta \mathrm{R}^{2}$ & $\Delta \mathrm{F}$ \\
\hline 1 & T1 PANAS-PA & .57 & .06 & .61 & $9.27^{\star * \star}$ & .38 & $85.93^{\star \star \star}$ \\
\hline \multirow[t]{2}{*}{2} & T1 SIAS & -.04 & .07 & -.05 & -.56 & .01 & .83 \\
\hline & T1 ERQ-Suppression & -.07 & .07 & -.08 & -.98 & & \\
\hline 3 & SIAS* ERQ-Suppression & .11 & .06 & .18 & $1.74+$ & .02 & $3.04+$ \\
\hline \multicolumn{8}{|c|}{ Moderator: Negative Emotional Expression } \\
\hline \multicolumn{2}{|l|}{ Step } & $\mathrm{b}$ & $\mathrm{SE}_{\mathrm{b}}$ & $\mathrm{pr}$ & $\mathrm{t}$ & $\Delta \mathrm{R}^{2}$ & $\Delta \mathrm{F}$ \\
\hline 1 & T1 PANAS-PA & .58 & .06 & .62 & $9.32^{* * *}$ & .38 & $86.84^{* * *}$ \\
\hline \multirow[t]{2}{*}{2} & T1 SIAS & -.05 & .07 & -.06 & -.67 & .01 & 1.27 \\
\hline & T1 BEQ-Negative & .08 & .06 & .11 & 1.33 & & \\
\hline 3 & SIAS*BEQ-Negative & -.10 & .05 & -.16 & $-1.90+$ & .02 & $3.60+$ \\
\hline \multicolumn{8}{|c|}{ Moderator: Positive Emotional Expression } \\
\hline \multicolumn{2}{|l|}{ Step } & $\mathrm{b}$ & $\mathrm{SE}_{\mathrm{b}}$ & $\mathrm{pr}$ & $t$ & $\Delta \mathrm{R}^{2}$ & $\Delta \mathrm{F}$ \\
\hline 1 & T1 PANAS-PA & .58 & .06 & .62 & $9.32^{* \star *}$ & .38 & $86.84^{\star * *}$ \\
\hline \multirow[t]{2}{*}{2} & T1 SIAS & -.06 & .07 & -.07 & -.88 & .01 & .78 \\
\hline & T1 BEQ-Positive & .06 & .06 & .08 & .89 & & \\
\hline 3 & SIAS*BEQ-Positive & -.14 & .06 & -.20 & $-2.36^{*}$ & .02 & $5.57^{\star}$ \\
\hline
\end{tabular}

Note. $N s=144,143$, and 143 , respectively. $+p \leq .08 .{ }^{*} p<.05 .{ }^{* *} p<.01 .{ }^{* \star *} p<.001$. All $p$-values were two-tailed.

We examined the level of independence between emotion suppression and tendencies to express negative and positive emotions. Zero-order correlations are reported in Table 1. A principal components exploratory factor analysis with an oblique (promax) rotation was conducted on measures of emotion suppression, negative emotional expression, and positive emotional expression. Results produced a single factor with an eigenvalue of 2.10 accounting for $69.93 \%$ of the variance (the next factor had an eigenvalue of .50). Observations of the scree plot supported a clear break after one factor, and the factor loadings for emotion suppression, negative expression, and positive expression were $-.78, .76$, and .68 , respectively. Findings provide evidence for a single bipolar dimension with tendencies to suppress and express emotions as endpoints. However, we examined these constructs as separate variables to further evaluate their independence. ${ }^{2} \Delta=.03, p=.02$.

\footnotetext{
${ }^{2}$ Based on the factor-analytic findings, we constructed an alternative model. ERQ-Suppression, BEQ-Negative Emotional Expression, and BEQ-Positive Emotional Expression were each transformed into $z$-scores and aggregated (ERQ-Suppression was reverse-scored and added to the other scales) to create a composite score. The moderator findings converged with those reported using the scales separately. After T1 levels of positive emotions and T1 main effects, respectively, accounted for $38 \%$ and $1 \%$ of the variance, the Social Anxiety x Emotion Expression Composite was statistically significant, $F \Delta(1,139)=5.82, R^{2} \Delta=.03, p=.02$. Specifically, people with excessive social anxiety and higher scores on the emotion expression composite reported the greatest increases in positive emotions over time. All findings are available upon request.
}

SOCIAL ANXIETY AND EMOTION PROCESSES AS PREDICTORS OF CHANGES IN POSITIVE EMOTIONS

We constructed three separate hierarchical regression models to examine whether T1 emotion suppression (ERQ subscale), T1 negative emotional expression (BEQ subscale), and T1 positive emotional expression (BEQ subscale) moderated the effects of social anxiety on changes in positive emotions. T2 positive emotions (PANAS subscale) served as the dependent variable. T1 (baseline) positive emotions were initially entered to create residual change scores from T1 to T2. After entering the T1 main effects, the relevant T1 Social Anxiety x T1 Emotion Process (Suppression, Negative Expression, or Positive Expression) interaction was entered. Predictor and outcome variables were centered and significant interaction effects were explored with simple effect analyses (see Aiken \& West, 1991). For each model, baseline T1 positive emotion accounted for substantial variance in $\mathrm{T} 2$ positive emotion (see Table 2).

\section{EMOTION SUPPRESSION}

We found support for emotion suppression as a moderator of the effects of social anxiety on changes in positive emotion over time. When conditioned at one standard deviation below the mean on social anxiety, less emotion suppression was related to greater positive emotions over time, $t(21)=-2.36$, $R^{2} \Delta=.17, p=.03$, whereas when conditioned at one standard deviation above the mean on social anxiety, emotion suppression had a nonsignificant relation 


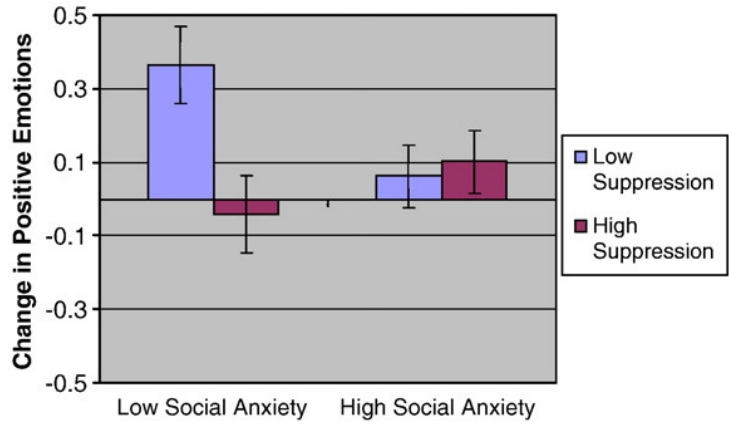

FIGURE I Residual Change in Positive Emotions as a Function of Social Anxiety and Emotion Suppression. (Predictor and criterion variables were transformed into $z$-scores prior to analyses. High and low social anxiety and high and low emotion suppression were each defined as at least $+\mid$ and $-\mid$ standard deviations from the mean.)

with changes in positive emotions $\left(R^{2} \Delta=.00\right.$, $p=.76)$. As presented in Figure 1, for low socially anxious individuals, less suppression was related to greater increases in positive emotions.

\section{NEGATIVE EXPRESSION}

We found support for negative emotional expression as a moderator of the effects of social anxiety on changes in positive emotion over time. When conditioned at one standard deviation below the mean on social anxiety, greater negative expression was related to greater positive emotions over time, $t(21)=2.62, R^{2} \Delta=.20, p=.02$, whereas when conditioned at one standard deviation above the mean on social anxiety, negative expression had a nonsignificant relation with changes in positive emotions $\left(R^{2} \Delta=.02, p=.34\right)$. As presented in Figure 2, for low socially anxious individuals, greater negative expression was related to greater increases in positive emotions.

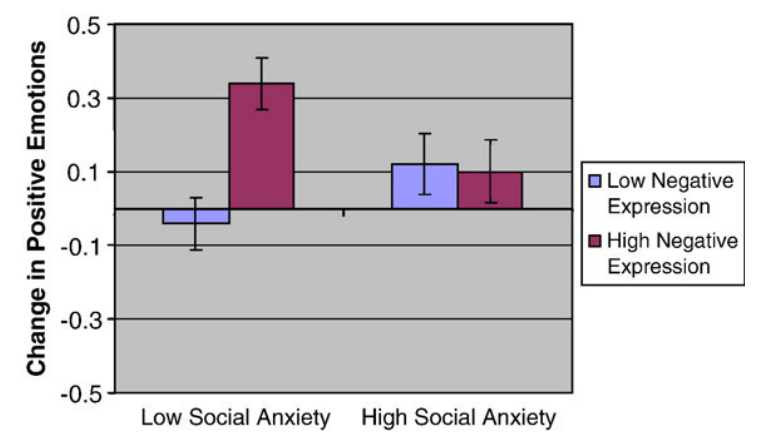

FIGURE 2 Residual Change in Positive Emotions as a Function of Social Anxiety and Negative Emotional Expression. (Predictor and criterion variables were transformed into $z$-scores prior to analyses. High and low social anxiety and high and low negative emotional expression were each defined as at least +1 and -1 standard deviations from the mean.)

\section{POSITIVE EXPRESSION}

We found support for positive emotional expression as a moderator of the effects of social anxiety on changes in positive emotion over time. When conditioned at one standard deviation below the mean on social anxiety, greater positive expression was related to greater positive emotions over time, $t(21)=3.08, R^{2} \Delta=.25, p<.01$, whereas when conditioned at one standard deviation above the mean on social anxiety, positive expression had a nonsignificant relation with changes in positive emotions $\left(R^{2} \Delta=.00, p=.74\right)$. As presented in Figure 3, for low socially anxious individuals, greater positive expression was related to greater increases in positive emotions.

\section{ADDITIONAL EXAMINATION OF HIGH SOCIALLY ANXIOUS INDIVIDUALS}

Why did high socially anxious individuals fail to show reductions in positive emotions over time, particularly those people with greater tendencies to suppress emotion or less tendencies to openly display emotions? One reason may be the presence of chronic, diminished positive psychological resources in high socially anxious individuals, from young adulthood onward. To examine this, we conducted a paired samples $t$-test on T1 and T2 positive emotions for high socially anxious individuals (scoring at least one standard deviation above the mean on the SIAS). For high socially anxious individuals, the mean scores on T1 and T2 positive emotions were 29.85 $(S D=6.58)$ and $31.80(S D=7.91)$, respectively; $r=.63, p<.001, t(25)=-1.58, p=.13$. Positive emotions were evaluated on a 1-5 Likert scale and for the high socially anxious group, $30.8 \%$ and $23.1 \%$ scored at or below the midpoint at T1 and T2, respectively. As a mode of comparison, we conducted similar analyses on the low socially anxious group

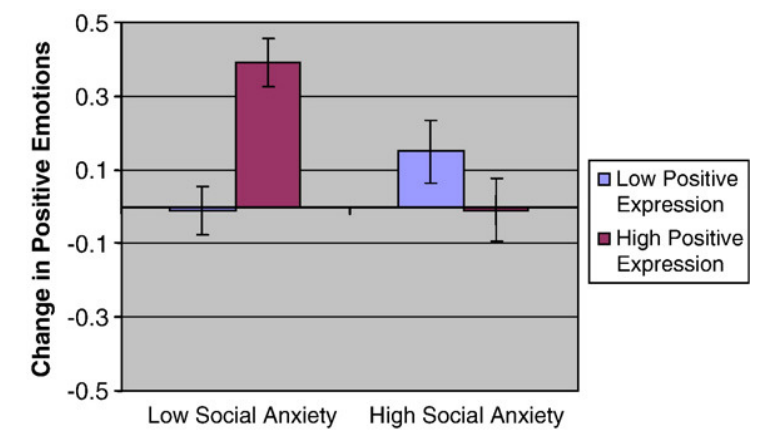

FIGURE 3 Residual Change in Positive Emotions as a Function of Social Anxiety and Positive Emotional Expression. (Predictor and criterion variables were transformed into $z$-scores prior to analyses. High and low social anxiety and high and low positive emotional expression were each defined as at least $+I$ and - I standard deviations from the mean.) 
(scoring at least one standard deviation below the mean on the SIAS). Compared to the high socially anxious group, we found slightly lower levels of intraindividual stability and greater mean positive emotion ratings. Specifically, for low socially anxious individuals, the mean scores on T1 and T2 positive emotions were $38.12(S D=4.26)$ and $38.19(S D=6.34)$, respectively; $r=.46, p=.03, t(23)=-.06, p=.95$. Additionally, for the low socially anxious group, $0 \%$ and $4.2 \%$ scored at or below the midpoint at T1 and T2, respectively.

\section{REVERSE CAUSATION MODEL}

It could be hypothesized that there is a bidirectional relation such that positive emotions or any of the Positive Emotion $\mathrm{x}$ Emotion Process interactions predicts changes in social anxiety. However, we found no support for positive emotion main or interaction effects in predicting changes in social anxiety $(p s>.80)$.

\section{SPECIFICITY OF SOCIAL ANXIETY EFFECTS}

The specificity of social anxiety effects were examined by repeating the foregoing analyses (a) controlling for the BDI-II as a covariate and (b) examining a Depressive Symptoms x Emotion Expression interaction effect on changes in positive emotions. Controlling for depressive symptoms had no influence on the Social Anxiety x Emotion Suppression $(p=.03)$, Social Anxiety $\mathrm{x}$ Negative Expression $(p=.07)$, or Social Anxiety $\mathrm{x}$ Positive Expression $(p=.02)$ interaction effects on positive emotions (i.e., no effect size reductions). As an additional test of specificity, the Depressive Symptom main and interaction effects failed to significantly predict changes in positive emotions ( $p s>.35$ ).

\section{Discussion}

There is now good evidence that social anxiety is associated with diminished positive experiences (Kashdan, 2007; Watson, Clark, \& Carey, 1988). The current study was the first to examine the longitudinal relation between social anxiety and positive emotions. We found support for a stable, moderately large inverse relation between social anxiety and positive emotions over a 12-week period. Further, consistent with our moderation model, less socially anxious adults who tend to openly express rather than suppress emotions demonstrated the greatest increases in positive emotions across the 12 -week period. In terms of alternative models of causation, we failed to find support for positive emotions, alone or in interaction with emotion suppression or expression tendencies, as predictors of change in social anxiety.
In terms of specificity, the main effect of social anxiety and the synergistic effects of social anxiety and emotion expression on positive emotions were not attributable to depressive symptoms. These tests of construct specificity can be considered conservative because of the content overlap between depressive symptoms and social anxiety and between anhedonic depressive symptoms and positive emotions. These findings contribute additional evidence to suggest that diminished positive emotions are characteristic of both depression and excessive social anxiety.

Perhaps the most valuable finding of this study was further evidence for an interactive model between social anxiety and the ways in which people monitor, regulate, and relate to emotions in predicting positive experiences and events (see Kashdan \& Steger, 2006, for initial evidence). Our data suggest that low levels of social anxiety alone were not sufficient to produce increased positive emotions across time. The combination of relatively low social anxiety along with tendencies to be more accepting and expressive of emotions led to the highest scores on the measure of positive emotion at T2. It appears that the different ways people choose to regulate their emotions and their outward expression are critical in facilitating positive psychological experiences. There are several benefits of not relying on tendencies to suppress emotions and of being more emotionally expressive. Laughing when something is humorous, hugging someone during moments of love or gratitude, or talking and gesturing with animation when feeling excitement and joy are all forms of creating and prolonging positive feelings. Displaying positive emotion is also an important process in identifying, developing, and maintaining friendships and romantic relationships (Keltner \& Haidt, 1999). On average, people prefer to be with more cheerful people and positive moods are contagious and easily transferred to others (Hatfield, Cacioppo, \& Rapson, 1994). Personal events are more meaningful and memorable to oneself and others when they are experienced with greater vitality and expressive-motor activity. When emotions are experienced and embraced with open and nonjudgmental attitudes toward emotional expression, events are not only more enjoyable but can serve as a mood-enhancement strategy when recalled and savored (reminiscing).

Besides being a marker of psychological wellbeing, high frequencies of positive emotion generate well-being. Whereas negative emotions function to narrow activity to specific environmental demands (e.g., fight-or-flight), there is evidence that positive emotions (a) induce a speedier recovery from the damaging physiological effects of negative emotions 
(e.g., Fredrickson, Mancuso, Branigan \& Tugade, 2000), (b) broaden attentional resources-increasing awareness during activities, the efficiency and quality of decision-making, and accessibility of more creative and flexible options in a given situation (Fredrickson \& Branigan, 2005; Isen, 1993), (c) build social bonds (e.g., Aron et al., 2000), and (d) stimulate resilience to negative life events (e.g., Tugade \& Fredrickson, 2004). Positive emotions and their functions are not reducible to minimal social anxiety or distress. However, socially anxious people can be expected to vary in their capacity and experience of positive emotions. It will be important to examine the personal and situational factors that confer opportunities for the development of positive experiences in high socially anxious individuals. Specifically, more research is needed on how people with excessive social anxiety experience positive emotions and how these states are maintained (or conversely, disrupted), and to what extent emotional experiences and self-regulatory processes operate together. To understand the scope of emotion regulation in social anxiety, it will be necessary to account for differences between deliberate, effortful regulatory strategies and automatic, spontaneous processes (Forgas, 1995).

Contrary to our joint vulnerability hypothesis, neither social anxiety nor the interaction between social anxiety and suppression/expression tendencies predicted decreases in positive emotions over time. Instead, we found high socially anxious individuals to report stable, low levels of positive emotions. The chronic, low vitality of high socially anxious individuals can be expected to constrain their capacity to self-regulate effectively. High socially anxious individuals are overly concerned about the possibility of social rejection and, in response, engage in extensive efforts to control their anxiety and demonstrate impression management (Clark \& Wells, 1995; Leary \& Kowalski, 1995). In fact, we found tendencies to suppress emotions to be strongly correlated with greater social anxiety. Impression management and attempts to control and change emotions require and deplete self-regulatory resources (e.g., vitality, cognitive capacity). Tendencies to suppress emotions and other self-protective strategies are not inherently harmful. However, engaging in specific behavior strategies chronically and inflexibly with the goal of avoiding social disapproval may lead to a cycle of (a) depleted self-regulatory resources and positive emotions, (b) avoidance behaviors that reduce opportunities for positive emotions and events, and (c) selecting activities that prevent anxiety at the expense of doing things that are congruent with intrinsic values (i.e., giving up things that are potentially enjoyable because they require some degree of anxiety or risk). More complex structural modeling can examine the roles of self-regulatory processes and resource depletion as etiologic and maintenance factors in excessive social anxiety.

There are several possibilities as to why there was no support for a joint vulnerability model. The stable, low positive emotions of people with excessive social anxiety may reflect a floor effect with little possibility for further erosion. People with excessive social anxiety also tend to have negative interpretation biases that can affect reporting accuracy and lead to the minimization and mental filtering of positive experiences. Alternatively, for people suffering from impairing social anxiety, sources of positive experiences may already be substantially depleted. The average age of onset of impairing social anxiety is in early to mid-adolescence (Schneier, Johnson, Hornig, Liebowitz, \& Weissman, 1992). It is likely that socially anxious college students and older adults have already modified their behavior to avoid feeling anxious while maintaining a level of engagement in fundamental life areas such as work, social relationships, and play. There are few studies examining the impact of emotion disturbances on positive psychological functioning. Thus, we know very little about how social anxiety affects life trajectories and creates discrepancies between actual and ideal/ desired goals and behaviors. Future work may examine erosive processes over a longer time frame, at earlier life stages, and during meaningful life transitions (e.g., from high school to college, college to work force, retirement) when social anxiety and habitual emotional tendencies are more variable.

There are a few caveats to be considered in the interpretation of our findings. We relied exclusively on self-report. Although there is no better way to examine the subjective component of emotions (Watson, 2000), it will be important for future research to use alternative methodologies to measure the experience of pleasure. In terms of social anxiety, self-report measures cannot adequately assess functional impairment. However, the mean and range of social anxiety scores in our sample appear to have some generalizability to clinical populations (E. Brown et al., 1997). Although we used one of the most widely studied and psychometrically sound measures of positive emotions, the PANAS only measures activated or energized emotions and ignores the less energized quadrant of positive emotional experiences (e.g., serenity, calmness). Nonetheless, our interest was in energized positive emotions that capture vitality and enthusiasm, which appear to be fundamental to the optimal psychological states of intrinsic motivation and complete immersion in life experiences (Ryan \& 
Deci, 2000). There is merit in expanding the breadth of positive psychological constructs in the study of social anxiety. Despite the reliance on well-validated self-report methodologies, we believe it is valuable to determine how social anxiety and the reliance on different emotion regulatory strategies predict changes in positive emotions (for better or worse) over time as opposed to reactivity to laboratory stimuli at a single time point. For complex constructs such as self-regulatory strategies, there is merit in replicating and extending our work with experimental, multimethod designs that can better address issues related to causality.

There are some subsidiary issues worthy of discussion. Our data add to the literature on emotion regulation by showing convergence between emotion suppression and expression in terms of (a) strong negative correlations ( $r$ s ranged from -.53 to -.60 ), (b) factor analytic findings that support a single continuum from emotional acceptance to overregulation, and (c) similar roles as regulatory strategies that moderate the effect of social anxiety on changes in positive emotions over time. In other findings, both positive and negative emotional expression had the same type of moderating influence on relations between social anxiety and positive emotions. That is, greater expression, whether positive or negative, had a beneficial function for people with minimal social anxiety. Future studies would benefit from more rigorous, multimethod designs to explore the independence of aversive and appetitive activity. Although our findings are limited to self-report ratings, there is substantial evidence that these constructs can be adequately measured using self-report technologies (Gross \& John, 2003; John \& Gross, 2004).

The results of this study have implications for better understanding the phenomenology and consequences of social anxiety. Framed within a selfregulatory model, excessive social anxiety was associated with stable, low levels of positive emotions across a 12-week interval. Additionally, low social anxiety and more open expression and display of emotions, or a relative absence of a tendency to suppress emotions, contributes to the development of positive emotions over time. Over the past few decades, it has been theorized that positive emotions are only relevant to depressive symptoms and not anxiety. Our data suggest that positive emotions are compromised in people with high social anxiety, that low social anxiety relates to greater positive emotions in the presence of certain affect-regulatory strategies, and that the magnitude of these findings were not attributable to individual differences in depressive symptoms. It seems clear that individual differences in social anxiety and regulatory strategies affect positive psychological functioning. Future empirical work should continue to explore the interplay among these processes and, with further replication, may present as useful targets of intervention.

\section{References}

Aiken, L. S., \& West, S. G. (1991). Multiple regression: Testing and interpreting interactions. London: Sage.

Alden, L. E., \& Taylor, C. T. (2004). Interpersonal processes in social phobia. Clinical Psychology Review, 24, 857-882.

Arkin, R. M. (1981). Self-presentational styles. In J. T. Tedeschi (Ed.), Impression management theory and social psychological research (pp. 311-333). New York: Academic Press.

Aron, A., Norman, C. C., Aron, E. N., McKenna, C., \& Heyman, R. (2000). Couples shared participation in novel and arousing activities and experienced relationship quality. Journal of Personality and Social Psychology, 78, 273-283.

Baumeister, R., \& Leary, M. R. (1995). The need to belong: Desire for interpersonal attachments as a fundamental human motivation. Psychological Bulletin, 117, 497-529.

Baumeister, R. F., \& Tice, D. M. (1990). Anxiety and social exclusion. Journal of Social and Clinical Psychology, 9, 165-196.

Beck, A. T., Steer, R. A., \& Brown, G. K. (1996). Beck Depression Inventory manual, 2nd ed. San Antonio, TX: Psychological Corporation.

Behar, E., Vescio, T. K., \& Borkovec, T. D. (2005). The effects of suppressing thoughts and images about worrisome stimuli. Behavior Therapy, 36, 289-298.

Brown, E. J., Turovsky, J., Heimberg, R. G., Juster, H. R., Brown, T. A., \& Barlow, D. H. (1997). Validation of the Social Interaction Anxiety Scale and the Social Phobia Scale across the anxiety disorders. Psychological Assessment, 9, 21-27.

Brown, T. A., Chorpita, B. F., \& Barlow, D. H. (1998). Structural relationships among dimensions of the DSM-IV anxiety and mood disorders and dimensions of negative affect, positive affect, and autonomic arousal. Journal of Abnormal Psychology, 107, 179-192.

Burns, D. D., \& Eidelson, R. J. (1998). Why are depression and anxiety correlated? A test of the tripartite model. Journal of Consulting and Clinical Psychology, 66, 461-473.

Cartensen, L. L., Gottman, J. M., \& Levenson, R. W. (1995). Emotional behavior in long-term marriage. Journal of Personality and Social Psychology, 10, 140-149.

Clark, D. A., Steer, R. A., \& Beck, A. T. (1994). Common and specific dimensions of self-reported anxiety and depression: Implications for the cognitive and tripartite models. Journal of Abnormal Psychology, 103, 645-654.

Clark, D. M., \& Wells, A. (1995). A cognitive model of social phobia. In R. G. Heimberg, M. R. Liebowitz, D. A. Hope, \& F. R. Schneier (Eds.), Social phobia: Diagnosis, assessment, and treatment (pp. 69-94). New York: The Guilford Press.

Clark, L. A., \& Watson, D. (1991). Tripartite model of anxiety and depression: Psychometric evidence and taxonomic implications. Journal of Abnormal Psychology, 100, 316-336.

Davidson, R. J. (1994). Asymmetric brain function, affective style, and psychopathology: The role of early experience and plasticity. Development and Psychopathology, 6, 741-758.

Eifert, G. H., \& Forsyth, J. P. (2005). Acceptance and Commitment Therapy for anxiety disorders: A practitioner's treatment guide using mindfulness, acceptance, and values based behavior change strategies. Oakland, CA: New Harbinger. 
Fehm, L., \& Margraf, J. (2002). Thought suppression: Specificity in agoraphobia versus broad impairment in social phobia? Behaviour Research and Therapy, 40, 57-66.

Feldner, M. T., Zvolensky, M. J., Eifert, G. H., \& Spira, A. P. (2003). Emotional avoidance: An experimental test of individual differences and response suppression during biological challenge. Behaviour Research and Therapy, 41, 403-411.

Feldner, M. T., Zvolensky, M. J., Stickle, T. R., Bonn-Miller, M. O., \& Leen-Feldner, E. W. (2006). Anxiety sensitivityphysical concerns as a moderator of the emotional consequences of emotion suppression during biological challenge: An experimental test using individual growth curve analysis. Behaviour Research and Therapy, 44, 249-272.

Forgas, J. P. (1995). Mood and judgment: The affect infusion model (AIM). Psychological Bulletin, 117, 39-66.

Fredrickson, B. L., \& Branigan, C. (2005). Positive emotions broaden the scope of attention and thought-action repertoires. Cognition and Emotion, 19, 313-332.

Fredrickson, B. L., Mancuso, R. A., Branigan, C., \& Tugade, M. M. (2000). The undoing effect of positive emotions. Motivation and Emotion, 24, 237-258.

Frijda, N. H. (1986). The emotions. New York: Cambridge University Press.

Gross, J. J. (1998). The emerging field of emotion regulation: An integrative review. Review of General Psychology, 2, 271-299.

Gross, J. J., \& John, O. P. (1995). Facets of emotional expressivity: Three self-report factors and their correlates. Personality and Individual Differences, 19, 555-568.

Gross, J. J., \& John, O. P. (1997). Revealing feelings: Facets of emotional expressivity in self reports, peer ratings, and behavior. Journal of Personality and Social Psychology, 72, 435-448.

Gross, J. J., \& John, O. P. (2003). Individual differences in two emotion regulation processes: Implications for affect, relationships, and well-being. Journal of Personality and Social Psychology, 85, 348-362.

Gross, J. J., \& Levenson, R. W. (1993). Emotional suppression: Physiology, self-report, and expressive behavior. Journal of Personality and Social Psychology, 64, 970-986.

Gross, J. J., \& Levenson, R. W. (1997). Hiding feelings: The acute effects of inhibiting negative and positive emotion. Journal of Abnormal Psychology, 106, 95-103.

Harris, C. R. (2001). Cardiovascular responses of embarrassment and effects of emotional suppression in a social setting. Journal of Personality and Social Psychology, 81, 886-897.

Hatfield, E., Cacioppo, J., \& Rapson, R. (1994). Emotional contagion. New York: Cambridge Press.

Hayes, S. C., Luoma, J., Bond, F., Masuda, A., \& Lillis, J. (2006). Acceptance and Commitment Therapy: Model, processes, and outcomes. Behaviour Research and Therapy, $44,1-25$.

Hayes, S. C., Wilson, K. G., Gifford, E. V., Follette, V. M., \& Strosahl, K. (1996). Experiential avoidance and behavioral disorders: A functional dimensional approach to diagnosis and treatment. Journal of Consulting and Clinical Psychology, 64, 1152-1168.

Heimberg, R. G., Mueller, G. P., Holt, C. S., Hope, D. A., \& Liebowitz, M. R. (1992). Assessment of anxiety in social interaction and being observed by others: The Social Interaction Anxiety Scale and the Social Phobia Scale. Behavior Therapy, 23, 53-73.

House, J. S., Landis, K. R., \& Umberson, D. (1988). Social relationships and health. Science, 241, 540-545.

Isen, A. M. (1993). Positive affect and decision making. In
M. Lewis, \& J. M. Haviland (Eds.), Handbook of emotions (pp. 261-277). New York: The Guilford Press.

John, O. P., \& Gross, J. J. (2004). Healthy and unhealthy emotion regulation: Personality processes, individual differences, and lifespan development. Journal of Personality, 72, 1301-1334.

Kashdan, T. B. (2007). Social anxiety spectrum and diminished positive experiences: Theoretical synthesis and meta-analysis. Clinical Psychology Review, 27, 348-365.

Kashdan, T. B., \& Steger, M. (2006). Expanding the topography of social anxiety: An experience sampling assessment of positive emotions and events, and emotion suppression. Psychological Science, 17, 120-128.

Kashdan, T. B., Volkmann, J. R., Breen, W. E., \& Han, S. (2007). Social anxiety and romantic relationships: The costs and benefits of negative emotion expression are contextdependent. Journal of Anxiety Disorders, 21, 475-492.

Keltner, D., \& Haidt, J. (1999). The social functions of emotions at four levels of analysis. Cognition and Emotion, $13,505-522$.

Langston, C. A. (1994). Capitalizing on and coping with dailylife events: Expressive responses to positive events. Journal of Personality and Social Psychology, 67, 1112-1125.

Leary, M. R., \& Kowalski, R. M. (1995). The self-presentation model of social phobia. In R. G. Heimberg, M. R. Liebowitz, D. A. Hope, \& F. R. Schneier (Eds.), Social phobia: Diagnosis, assessment, and treatment (pp. 94-112). New York: The Guilford Press.

Levenson, R. W., \& Gottman, J. M. (1985). Physiological and affective predictors of change in relationship satisfaction. Journal of Personality and Social Psychology, 49, 85-94.

Mattick, R. P., \& Clarke, J. C. (1998). Development and validation of measures of social phobia scrutiny fear and social interaction anxiety. Behaviour Research and Therapy, $36,455-470$.

Muraven, M., \& Baumeister, R. F. (2000). Self-regulation and depletion of limited resources: Does self-control resemble a muscle? Psychological Bulletin, 126, 247-259.

Nezlek, J., \& Leary, M. R. (2002). Individual differences in selfpresentational motives in daily social interaction. Personality and Social Psychology Bulletin, 28, 211-223.

Peters, L. (2000). Discriminant validity of the Social Phobia and Anxiety Inventory (SPAI), the Social Phobia Scale (SPS) and the Social Interaction Anxiety Scale (SIAS). Behaviour Research and Therapy, 38, 943-950.

Ryan, R. M., \& Deci, E. L. (2000). Self-determination theory and the facilitation of intrinsic motivation, social development, and well-being. American Psychologist, 55, 68-78.

Schneier, F. R., Johnson, J., Hornig, C. D., Liebowitz, M. R., \& Weissman, M. M. (1992). Social phobia: Comorbidity and morbidity in an epidemiologic sample. Archives of General Psychiatry, 49, 282-288.

Sprinkle, S. D., Lurie, D., Insko, S. L., Atkinson, G., Jones, G. L., Logan, A. R., \& Bissada, N. N. (2002). Criterion validity, severity cut scores, and test-retest reliability of the Beck Depression Inventory-II in a university counseling center sample. Journal of Counseling Psychology, 49, 381-385.

Strack, F., Martin, L. L., \& Stepper, S. (1988). Inhibiting and facilitating conditions of the human smile: A nonobtrusive test of the facial feedback hypothesis. Journal of Personality and Social Psychology, 54, 768-777.

Tugade, M. M., \& Fredrickson, B. L. (2004). Resilient individuals use positive emotions to bounce back from negative emotional experiences. Journal of Personality and Social Psychology, 86, 320-333.

Turk, C. L., Heimberg, R. G., Luterek, J. A., Mennin, D. S., \& Fresco, D. M. (2005). Emotion dysregulation in generalized 
anxiety disorder: A comparison with social anxiety disorder. Cognitive Therapy and Research, 29, 89-106.

Vohs, K. D., Baumeister, R. F., \& Ciarocco, N. (2005). Selfregulation and self-presentation: Regulatory resource depletion impairs impression management and effortful selfpresentation depletes regulatory resources. Journal of Personality and Social Psychology, 33, 632-657.

Vujanovic, A. A., Zvolensky, M. J., Bernstein, A., Feldner, M. T., $\&$ McLeish, A. C. (2007). A test of the interactive effects of anxiety sensitivity and mindful attention in the prediction of anxious arousal, agoraphobic cognitions, and body vigilance. Behaviour Research and Therapy, 45, 1393-1400.

Watson, D. (2000). Mood and temperament. New York: The Guilford Press.

Watson, D., Clark, L. A., \& Carey, G. (1988). Positive and negative affect and their relation to anxiety and depressive disorders. Journal of Abnormal Psychology, 97, 346-353.

Watson, D., Clark, L. A., \& Tellegen, A. (1988). Development and validation of brief measures of positive and negative affect: The PANAS. Journal of Personality and Social Psychology, 54, 1063-1070.

Watson, D., Clark, L. A., Weber, K., Assenheimer, J. S., Strauss, M. E., \& McCormick, R. A. (1995). Testing a tripartite model: II. Exploring the symptom structure of anxiety and depression in student, adult, and patient samples. Journal of Abnormal Psychology, 104, 15-25.

Wegner, D. M., Schneider, D. J., Carter, S., \& White, T. (1987). Paradoxical effects of thought suppression. Journal of Personality and Social Psychology, 53, 5-13.

Wittchen, H. U., \& Beloch, E. (1996). The impact of social phobia. International Clinical Psychopharmacology, 11, $15-23$.

Received: October 2, 2006

AcCepted: February 4, 2007

Available online 29 October 2007 